\title{
Effects of oral administration of essential oils on anti- immune stress, antimicrobial and repairing the intestinal damage in broilers challenged by lipopolysaccharide
}

\begin{tabular}{|r|l|}
\hline Journal: & Canadian Journal of Animal Science \\
\hline Manuscript ID & CJAS-2018-0055.R2 \\
\hline Manuscript Type: & Article \\
\hline Author: & 26-Sep-2018 \\
\hline Complete List of Authors: & $\begin{array}{l}\text { LIU, SHUDONG; Chungbuk National University, animal science } \\
\text { Song, M. H.; Chungnam National University, Swine Nutrition } \\
\text { YUN, WON; Chungbuk National University, animal science } \\
\text { Lee, JiHwan; Chungbuk National University, Animal Science } \\
\text { Kim, Hyeun Bum; Dankook University, } \\
\text { Cho, Jin Ho }\end{array}$ \\
\hline Keywords: & broilers, oral administration, essential oils, LPS, stress reaction \\
\hline &
\end{tabular}

\section{SCHOLARONE \\ Manuscripts}


Running title: Essential oils in broilers

Effects of oral administration of essential oils on anti-immune stress, antimicrobial and repairing the intestinal damage in broilers challenged by lipopolysaccharide

S.D. Liu ${ }^{1, *} ;$ M. H. Song ${ }^{2, *}$; W. Yun ${ }^{1}$; J.H. Lee ${ }^{1} ;$ H. B. Kim ${ }^{3, \#}$ and J.H. Cho ${ }^{1, \#}$

${ }^{1}$ Division of Food and Animal Science, Chungbuk National University, Cheongju-si, Republic of Korea, 361-763,

${ }^{2}$ Department of Animal Science and Biotechnology, Chungnam National University, Daejeon, 305-764, Republic of Korea

${ }^{3}$ Department of Animal Resource and Science; Dankook University, Cheonan,330-714; Republic of Korea

*Those authors contributed equally to this work.

\#Corresponding author: Jinho Cho, jinhcho@chungbuk.ac.kr; Co-Corresponding author: HyeunBum Kim, hbkim@dankook.ac.kr 


\section{Abstract}

The aim of the present study was to evaluate the effects of oral administration of essential oils (carvacrol, thyme and oregano essential oils) on anti-immune stress, antimicrobial and repairing the intestinal damage that caused by Salmonella enterica Lipopolysaccharide (LPS) in broilers. A total of 100 ROSS 308 broilers (21-day-old; $1.10 \pm 0.11 \mathrm{~kg}$ ) were randomly allocated to 5 groups, T1: basal diet + Saline; T2: basal diet + LPS; T3: basal diet $+200 \mu$ L carvacrol oils + LPS; T4: basal diet $+200 \mu$ L thyme oils + LPS; T5: basal diet + $200 \mu \mathrm{L}$ oregano oils + LPS, with 20 replicates every group, and 1 chicken per replicate per cage. The challenged by LPS resulted in an immune stress, which manifests as the abnormal growth $(\mathrm{P}<0.05)$ in immune organs, the content of $\operatorname{IgG}(\mathrm{P}<0.05)$ and TNF- $\alpha$ $(\mathrm{P}<0.05)$ and the rectum temperature $(\mathrm{P}<0.05)$ increased compared with other groups, the oral administration of essential oils controlled the immune stress to a certain extent. The essential oils could withhold maleficent bacteria, as E.coli $(\mathrm{P}<0.05)$ and Salmonella enumeration $(\mathrm{P}<0.05)$, in vivo of broilers. Meanwhile, the essential oils repaired the intestinal damage which shown a reduction in the villi height $(\mathrm{P}<0.05)$ and goblet cell $(\mathrm{P}<0.05)$ caused by LPS. In conclusion, the essential oils (carvacrol, thyme and oregano essential oils) controlled the stress reaction and maintain intestinal health to a certain extent.

Keywords: Broilers; Oral administration; Essential oils; LPS; Stress reaction 
Essential oil, also called volatile or ethereal oil, is aromatic liquid which is extracted from all parts of plant (Burt, 2004). It is a mixture that including alcohols, aldehydes, acids, phenols, acetone and terpenes, moreover, some laboratory studies have shown that it has antimicrobial, antioxidant and anti-inflammatory action (Abe et al., 2003; Scur et al., 2016). The antimicrobial action of phenols is the best among all ingredients of essential oils. It is reported that the blend of essential oils, added as feed supplementation, have a positive effect on the growth performance of broilers (Reisinger et al., 2011). Furthermore, essential oils have an anti-inflammatory function improving the immunity of body. Although there have many studies in the literature involving the addition of essential oils in diet, there is a lack of information on the effects of direct oral administration of these substances.

Lipopolysaccharide ( LPS ) (also called Endotoxins) is a vital component of cell wall of almost all Gram-negative bacteria, it is harmful and interacts with host effector cells resulting in the body has reaction of immunological stress (Tran and Whitfield, 2009). As a result, febrile reaction and leukocyte reaction are appeared, and may even cause septic shock in severe cases.

The purpose of direct oral administration of essential oils is to ensure that broilers can feed the same dosage of essential oils, no one of the broilers feeds different dosage because the individual feed intake is different. The objective of this study was not only to evaluate the effects of immune stress and intestinal damage caused by LPS in broiler, but to evaluate the effects of oral administration of essential oils (carvacrol, thyme and oregano essential oils) on anti-immune stress, antimicrobial and repairing the intestinal damage in vivo of 
broilers.

\section{MATERIAL AND METHODS}

The experimental protocol used in this study was approved by the Animal Care and Use Committee of Chungbuk National University.

\section{Experimental animals and treatment}

100 healthy mixed sex 21-day-old Ross 308 broiler chickens (initial body weight: $1.10 \pm 0.11 \mathrm{~kg}$ ) were obtained from the YangJi Company (Cheonan, Choongnam, South Korea) and were randomly allocated to 5 treatments, each of treatment consisted of 20 replicate cages with 1 broiler per cage (every treatment included 10 male and 10 female birds). Broilers were raised in a temperature-controlled room maintained at $24 \pm 1^{\circ} \mathrm{C}$. The relative humidity was approximately $50 \pm 5 \%$. The 5 treatments are as follows:

T1: Basal diets $+200 \mu \mathrm{L}$ Distilled water + Saline

T2: Basal diets $+200 \mu \mathrm{L}$ Distilled water $+L P S$

T3: Basal diets $+200 \mu \mathrm{L}$ Carvacrol essential oil + LPS

T4: Basal diets $+200 \mu \mathrm{L}$ Thyme essential oil + LPS

T5: Basal diets $+200 \mu \mathrm{L}$ Oregano essential oil + LPS

The broilers were fed the same diet throughout the 15-day experimental period. The basal diet was a kind of commercial available complete formula granulated feed which was supported by AT feed Company (Cheonsju, South Korea) and meeting or exceeding the recommended nutrient contents according to NRC (1994) for broiler (Table 1). Two groups (T1 and T2) were received oral administration of $200 \mu \mathrm{L}$ distilled water and other three 
groups (T3, T4 and T5) were received oral administration of three kinds of $200 \mu \mathrm{L}$ essential oils (Carvacrol essential oils: contain 50\% carvacrol; Thyme essential oils: contain $60 \%$ thymol and Oregano essential oil mainly containing $30.73 \%$ of carvacrol, $18.81 \%$ of thymol, 10.88\% of P-cymene; Skin-mate Corporation, Bucheon, South Korea) at 18:00 every day, respectively. On the 15 th day, intramuscular injection of $2 \mathrm{ml}$ Salmonella enterica LPS were conducted in four groups (T2, T3, T3, T4), $2 \mathrm{ml}$ saline for $\mathrm{T} 1$.

\section{Sample collection}

10 broilers ( 5 male and 5 female) were randomly selected from each group after injecting saline or LPS $2 \mathrm{~h}$. Blood samples were collected from the wing vein into a sterile syringe, at the time of collection, blood samples were collected into both no heparinized tubes and vacuum tubes containing Tripotassium-Ethylene-Diamine-Tetraacetic-Acid (K3EDTA; Becton, Dickinson and Co., Franklin Lakes, NJ, USA) to obtain serum and whole blood, respectively. The concentrations of white blood cells (WBC), lymphocyte and tumor necrosis factor- $\alpha(\mathrm{TNF}-\alpha)$ in the serum samples were analyzed with an automatic biochemical analyzer (RA-1000, Bayer Corp., Tarrytown, NY, USA)

After blood collection, the same broilers were euthanized by an intravenous injection of pentobarbital, with cervical dislocation to confirm death. The bursa of Fabricius, liver and spleen were then removed by trained personnel and weighed. During necropsy of 10 broilers from every treatment, the gastrointestinal tract was removed and duodenum (corresponding to the portion of the small intestine situated between the pylorus and the end of the duodenal loop). Segments $1 \mathrm{~cm}$ long were taken from the center of this part and 
fixed in $10 \%$ buffered formalin, embedded in paraffin wax, sectioned at $3 \mu \mathrm{m}$ and stained with hematoxylin-eosin. Histological sections were examined with a Nikon phase contrast light microscope coupled with a micro comp integrated digital imaging analysis system (Nikon Eclipse 80i, Nikon Co., Tokyo, Japan). Images were viewed using a 4x EPlan objective $(40 \times)$ to measure morphometric parameters of intestinal architecture. For this purpose, three favorably orientated sections cut perpendicularly from villus enterocytes to the muscular is mucosa were selected from every animal and measurements were carried out as follows: villous height $(\mathrm{VH})$ was estimated by measuring the vertical distance from the villous tip to villous-crypt junction level for 10 villi per section.

Digesta was collected by flushing contents from the gizzard, upper (to) and lower (from Meckel's Diverticulum) small intestine. Digesta samples were stored at $-80{ }^{\circ} \mathrm{C}$ before being frozen in liquid nitrogen and freeze-dried, for later microbial enumeration. The digesta sample (1g) from every bird was diluted was diluted with $9 \mathrm{ml}$ of $1 \%$ peptone broth (Becton, Dickinson and Co.) and homogenized. Viable counts of bacteria in the fecal samples were then determined by plating serial 10 -fold dilutions (in $1 \%$ peptone solution) onto MacConkey agar plates (Difco Laboratories, Detroit, MI, USA) and lactobacilli medium III agar plates (Medium 638, DSMZ, Braunschweig, Germany) to isolate Escherichia coli (E.coli) and Lactobacillus, respectively. The lactobacilli medium III agar plates were then incubated for $48 \mathrm{~h}$ at $39^{\circ} \mathrm{C}$ under anaerobic conditions. The MacConkey agar plates were incubated for $24 \mathrm{~h}$ at $37^{\circ} \mathrm{C}$. Escherichia coli and Lactobacillus colonies were counted immediately after removal from the incubator. For Salmonella, the serially 
diluted peptone broth tubes were incubated overnight at $37^{\circ} \mathrm{C}$, after which $1 \mathrm{ml}$ was transferred to $9 \mathrm{ml}$ of tetrathionate broth (Neogen Corporation, Lansing, MI, USA) and then incubated for $48 \mathrm{~h}$ at $42^{\circ} \mathrm{C}$. From these tubes, $1 \mathrm{ml}$ was used to inoculate $9 \mathrm{ml}$ of Rappaport Vassiliadis broth (Neogen Corporation, Lansing, MI, USA) and incubated for $48 \mathrm{~h}$ at $42^{\circ} \mathrm{C}$. The Rappaport was used to inoculate XLT4 plates for Salmonella isolation, and the Salmonella was, then, presumably identified using LIS and TSI agar tubes (Difco Laboratories, Detroit, MI, USA).

\section{Statistical analysis}

All data was conducted with and analyzed by ANOVA using SPSS (SPSS 22.0). Differences among the groups were determined using Ducan's multiple-range test. The data was presented as Means $\pm \mathrm{SD}$, and the differences between treatments were considered statistically significant if $\mathrm{P}<0.05$.

\section{RESULTS}

\section{Immune stress}

The effects of oral administration of various essential oils on immune organ weight in broilers challenged by Lipopolysaccharide (LPS) are shown in Table2. There was no significant difference on liver weight among each treatment $(\mathrm{P}>0.05)$. The challenged by LPS without essential oils (T2) significantly increased the spleen and bursa weight by $34.06 \%$ $(\mathrm{P}<0.05)$ and 57.26\% $(\mathrm{P}<0.05)$, respectively, when compared with $\mathrm{T} 1(\mathrm{P}<0.05)$. The spleen and bursa weight in $\mathrm{T} 3$ or T5 group did not have significant different in comparison with $\mathrm{T} 1(\mathrm{P}>0.05)$. However, the spleen weight in T4 group was significant higher than $\mathrm{T} 1$ 
$(\mathrm{P}<0.05)$.

The effects of oral administration of various essential oils on blood metabolites of broilers challenged by Lipopolysaccharide are shown in Table3. The content of IgG in the T2 and T5 group were higher than that of the T1 $(\mathrm{P}<0.05)$; however, the T3 and T4 did not have significant difference compared with the $\mathrm{T} 1$ or $\mathrm{T} 2(\mathrm{P}>0.05)$. There was no significant different $(\mathrm{P}>0.05)$ on WBC content among the groups. The challenged by LPS significantly increased the TNF- $\alpha$ content by $45.99 \%(\mathrm{P}<0.05)$ in comparison with the $\mathrm{T} 1$, but essential oils treatment groups did not have significant different $(\mathrm{P}>0.05)$ compared with the T1.

The effects of oral administration of various essential oils on rectum temperature in broilers challenged by Lipopolysaccharide are shown in Table 4. There was no significant difference $(\mathrm{P}>0.05)$ in rectum temperature among the treatments before injecting $L P S$, whereas the challenged by LPS significantly $(\mathrm{P}<0.05)$ increased the rectum temperature compared with other groups.

\section{Microbial enumeration}

The effects of oral administration of various essential oils on microbial enumeration in small intestine of broilers challenged by Lipopolysaccharide are shown in Table 5. There was no significant difference in Lactobacillus enumeration among each treatment $(\mathrm{P}>0.05)$, the challenged by LPS increased the Salmonella $(\mathrm{P}<0.05)$ and E. coli $(\mathrm{P}<0.05)$ counts when compared with $\mathrm{T} 1$; the oral administration of essential oils (carvacrol, thyme, oregano) significantly reduced the Salmonella $(\mathrm{P}<0.05)$ counts in comparison with the T2. The E. coli counts in the $\mathrm{T} 3$ was significantly reduced compared with the $\mathrm{T} 2(\mathrm{P}<0.05)$. 


\section{Intestinal mucosal morphology}

The effects of oral administration of various essential oils on small intestine mucosal morphology in broilers challenged by Lipopolysaccharide are shown in Table 6. The challenged by LPS reduced villus height $(\mathrm{P}<0.05)$ and goblet cell count $(\mathrm{P}<0.05)$ of small intestine in comparison with the T1. The oral administration of essential oils (T3, T4 and T5) significantly increased the goblet cell count of small intestine when compared with the $\mathrm{T} 1$ or $\mathrm{T} 2(\mathrm{P}<0.05)$.

\section{DISCUSSION}

\section{Anti-immune stress}

Spleen and bursa of Fabricius are immune organ in poultry, involving in the cellular immunity and humoral immunity of the body. It is reported that LPS challenge induces a significant increasing on spleen weight and bursa weight in broilers at early age (1-21d) (Li et al., 2015). In like manner, other report shown that LPS challenge can induce a significant increasing on bursa weight, but the liver weight and spleen weight do not have significant difference compared with non-LPS treatment (Wu et al., 2015). In short, LPS can induce the abnormal increasing in spleen and bursa, which is consistent with the current study. Moreover, the challenge increased the content of $\operatorname{IgG}(\mathrm{P}<0.05), \mathrm{WBC}(\mathrm{P}>0.05)$, Lymphocyte $(\mathrm{P}<0.05)$ and TNF- $\alpha(\mathrm{P}<0.05)$ in broilers, and significantly increased the body temperature $(\mathrm{P}<0.05)$. Accordingly and in view of the above-mentioned facts, it is speculated that the injecting LPS induce an immune stress which maybe stimulates the 
abnormal growth of immune organs, meanwhile, stimulates the secretion of immune factor, simultaneously result in an immune response which manifests as an increment in the rectum temperature.

Nitric oxide (NO), prostaglandins, and cytokines are involved in the inflammatory response. Nitric oxide synthase (NOS) and cyclooxygenase (COX) guidance synthesize of NO and prostaglandin, and they were induced by cyclooxygenase 2 (cox-2) and induced nitric oxide synthase (iNOS). Nuclear factor-kB (NF-kB) and mitogen activated protein kinase synthase (MAPKs) could trigger and regulate the signal transduction pathways of COX-2 and iNOS, and then implementation regulate the two enzymes activity or expression. Dung et al. (2009) found that essential oils from North Korea fir leaves could reduce the iNOS and COX-2 expression of mRNA and protein. Citral as active ingredient from cinnamon mountains could significantly inhibit the iNOS expression induced by LPS, but there was not has an effect on COX-2 expression. The oral administration of essential oils can resist the influence of LPS in broilers, the possible reason is that the active ingredient of essential oils could regulate the signal transduction pathways of COX-2 and iNOS, and then inhibit the inflammatory response. The results imply that injecting LPS can cause the stress reaction and increase the TNF- $\alpha$ secrete in broilers, and the oral administration of essential oils (carvacrol, thyme and oregano) can resist stress reaction and reduce the TNF- $\alpha$ secrete. The body temperature is increased as a result of the inflammatory or immune response, the mechanism could be that prostaglandin can rapidly act on the temperature sensitive neurons in hypothalamus causing a fever. It is reported that LPS-challenge increase the rectal 
temperature after injecting $4 \mathrm{~h}$ and $8 \mathrm{~h}$ (Liu et al., 2017). The results of current study have shown that oral administration of essential oils (carvacrol, thyme and oregano) keeps the temperature normal, it could be that the essential oils can regulate the pro-inflammatory cytokines, or just because it affects the process of the prostaglandin to action on the temperature neurons in hypothalamus.

\section{Anti-microbial}

LPS is the major component of the outer membrane of Gram-negative bacteria, contributing greatly to the structural integrity of the bacteria, and protecting the membrane from certain kinds of chemical attack. LPS increases the negative charge of the cell membrane and helps to stabilize the overall membrane structure. Injecting LPS cause an increment on harmful bacteria, as E. coli and Salmonella, in intestine of broiler. It could be that the endotoxins can break immune function of intestine leading to changes in intestinal environment, eventually, the harmful bacteria to multiply quicker. The current study agrees with previous study in the aspect that the supplementation of essential oils (including carvacrol and thymol) can reduce the E. coli count (Taylan and Bozkurt, 2009). Jang et al. (2007) found that the Colony-Forming Units (CFU) of E. coli is decreased by addition of essential oils. The most obvious reason for this phenomenon is that active ingredient of essential oils can change the cell membrane structure and conformation of bacteria, causing liquefaction and expansion of the cell membrane. Then the membrane will have less stability and higher permeability, leading to the leaking of intracellular important ion and contents ultimately to the death of the bacterial cell. 


\section{Intestine mucosal morphology}

The villus height is an important indicator of the digestive system health of broilers, and directly affects the absorptive capacity of the intestine mucosa membrane. Yamauchi et al. (2006) have reported that lower villus height leads to lower absorptive capability of the small intestine. Goblet cells can secrete sticky protein which have a protective effect on intestinal epithelium. According to the results from Table 5, the challenged by LPS caused an intestinal damage that reduction on the villus height and goblet cell of the small intestine. Same as previous studies that injecting LPS reduces the villus height of jejunum and ileum, but not significantly (Wang et al., 2016). One report has shown that the challenge by LPS significantly reduce villus height and goblet cell count of the intestine compared with nonLPS challenge groups (Wang et al., 2015). On account of the injection of LPS, as an exogenous endotoxin for the body, affects the intestinal integrity and permeability and there out we presume the endotoxin can impact or even kill the goblet cells, finally, leading to a reduction in villus height of intestine.

The supplementation of a blend of essential oils (contain $15 \mathrm{mg} / \mathrm{kg}$ of carvarcol) can significantly increase villus length and goblet cells count in broilers (Reisinger et al., 2011). In previous study, the wheat-based diet supplemented with essential oils ( $25 \%$ thyme and $25 \%$ carvacrol) can resist the $L P S$ challenge on villi height (Du et al., 2016). It is in line with our study: the oral administration of essential oils (carvacrol, thyme and oregano) can significantly increase villus height of duodenum $(\mathrm{P}<0.05)$, and counteract the intestinal damage caused by LPS in broilers, thus promoting the intestine development and health in 
the small intestine. This could be because the active ingredient of essential oils can impact or eliminate endotoxin, or just because it can promote the growth of goblet cells.

\section{CONCLUSION}

In conclusion, the injection of LPS causes the immunological stress in broilers and increase the Salmonella and E. coli count, has a negative effect on the mucosal morphology of small intestine. Oral administration of essential oils (carvacrol, thymol, oregano) resisted stress reaction, promoted the intestine development and health, reduced Salmonella and E. coli count.

\section{ACKNOWLEDGEM ENTS}

This study was carried out with the support of "National Research Foundation of Korea, Republic of Korea" and the Rural Development Administration (Project No. PJ012279).

\section{REFERENCES}

Abe S., Maruyama N., Hayama K., Ishibashi H., Inoue S., Oshima H., and Yamaguchi H., 2003. Suppression of tumor necrosis factor-alpha-induced neutrophil adherence responses by essential oils. Mediators of Inflammation. 12, 323-328,

Burt S., 2004. Essential oils: their antibacterial properties and potential applications in foods-a review. International Journal of Food Microbiology. 94, 223-253,

Du E., Wang W., Gan L., Li Z., Guo S., and Guo Y., 2016. Effects of thymol and carvacrol supplementation on intestinal integrity and immune responses of broiler chickens challenged with Clostridium perfringens. Journal of animal science and biotechnology. $7,19-29$ 
Dung, NT., Bajpai VK., Yoon JI., and Kang SC. 2009. Anti-inflammatory effects of essential oil isolated from the buds of Cleistocalyx operculatus (Roxb.) Merr and Perry. Food and chemical toxicology. 47, 449-453,

Jang IS., Ko YH., Kang SY., and Lee CY., 2007. Effect of a commercial essential oil on growth performance, digestive enzyme activity and intestinal microflora population in broiler chickens. Animal Feed Science and Technology, 134, 304-315

Li Y., Zhang H., Chen YP., Yang MX., Zhang LL., Lu ZX., Zhou YM., and Wang T., 2015. Bacillus amyloliquefaciens supplementation alleviates immunological stress in lipopolysaccharide-challenged broilers at early age. Poultry Science. 94, 1504-1511

Liu, S. D., Yun, W., Lee, J. H., Kwak, W. G., Oh, H. J., \& Lee, C. H., et al. (2017). Effects of microencapsulated organic acids and essential oils supplementation on performance and rectal temperature in challenged weaning pigs. Animal Production Science, 57(12), 2504.

National Research Council. 1994. Nutrient Requirements of Poultry. 9th rev. ed. National Academy Press, Washington, DC.

Reisinger N., Steiner T., Nitsch S., Schatzmayr G., and Applegate TJ., 2011. Effects of a blend of essential oils on broiler performance and intestinal morphology during coccidial vaccine exposure. The Journal of Applied Poultry Research, 20(3), 272-283

Scur MC., Pinto FG., Pandini JA., Costa WF., Leite CW., and Temponi LG., 2016. Antimicrobial and antioxidant activity of essential oil and different plant extracts of Psidium cattleianum Sabine. Brazilian Journal of Biology.76, 101-108 
Taylan AKSU., and Bozkurt AS., 2009. Effect of dietary essential oils and/or humic acids on broiler performance, microbial population of intestinal content and antibody titres in the summer season. Kafkas Universitesi Veteriner Fakaltesi Dergisi. 15, 185-190

Tran AX., and Whitfield C., 2009. Lipopolysaccharides (endotoxins). Encyclopedia of Microbiology, 71, 513-528

Wang W., Ren W., Li Z., Yue Y., and Guo Y., 2016. Effects of live yeast on immune responses and intestinal morphological structure in lipopolysaccharide-challenged broilers. Canadian Journal of Animal Science. 97,136-144

Wang X., Li Y., Shen J., Wang S., Yao J., and Yang X., 2015. Effect of Astragalus polysaccharide and its sulfated derivative on growth performance and immune condition of lipopolysaccharide-treated broilers. International journal of biological macromolecules, 76, 188-194

Wu QJ., Wang QY., Wang T., and Zhou YM., 2015. Effects of clinoptilolite (zeolite) on attenuation of lipopolysaccharide-induced stress, growth and immune response in broiler chickens. Annals of Animal Science. 15, 681-697

Yamauchi K., Buwjoom T., Koge K., and Ebashi T., 2006. Histological alterations of the intestinal villi and epithelial cells in chickens fed dietary sugar cane extract. British Poultry Science. 47, 544-553 
Table 1 Compositions of basal diets (as-fed basis)

\begin{tabular}{lc}
\hline Item & Ingredient $(\mathrm{g} / \mathrm{kg})$ \\
\hline Corn & 408.00 \\
Wheat & 200.00 \\
Soybean meal (CP 48\%) & 254.80 \\
Rape seed meal & 35.00 \\
Tallow & 60.10 \\
Limestone & 11.70 \\
Dicalcium phosphate & 18.40 \\
L-Lysine·HCl $(78.4 \%)$ & 2.00 \\
DL-Methionine $(88 \%)$ & 4.10 \\
Threonine $(98.5 \%)$ & 1.20 \\
Vitamin premix ${ }^{\mathrm{a}}$ & 0.30 \\
Trace Mineral premix ${ }^{\mathrm{b}}$ & 1.50 \\
Salt & 2.90 \\
Total & 1000.00 \\
Calculated composition $(\mathrm{g} / \mathrm{kg})$ & \\
ME, kcal/kg & 3180 \\
Analyzed composition $(\%)$ & \\
CP & 18.50 \\
Lysine & 1.10 \\
Met + Cys & 0.93 \\
Ca & 1.00 \\
Available P & 0.50 \\
Ether-extract & 7.96 \\
Crude Fibre & 3.25 \\
\hline Vitamin prenix provited & \\
\hline
\end{tabular}

a Vitamin premix provided per kg of complete diet: $15000 \mathrm{IU}$ of trans-retinol, $3750 \mathrm{IU}$ of cholecalciferol; $37.50 \mathrm{mg}$ of tocopherol; $2.55 \mathrm{mg}$ of menadione; $3.00 \mathrm{mg}$ of thiamine; $7.50 \mathrm{mg}$ of riboflavin; $4.50 \mathrm{mg}$ of pyridoxine; and $24.00 \mu \mathrm{g}$ of cobalamin; $51.00 \mathrm{mg}$ of niacin; $1.50 \mathrm{mg}$ of folic acid; $126.00 \mathrm{mg}$ of biotin; and $13.5 \mathrm{mg}$ of pantothenic acid.

b Provided per kg of complete diet: $\mathrm{Zn}\left(\right.$ as $\mathrm{ZnSO}_{4}$ ), $37.50 \mathrm{mg}$; $\mathrm{Cu}$ (as $\mathrm{CuSO}_{4} \cdot 5 \mathrm{H}_{2} \mathrm{O}$ ), 26.00mg; $\mathrm{Mn}$ (as $\mathrm{MnO}_{2}$ ), $137.50 \mathrm{mg}$; $\mathrm{Fe}$ (as $\mathrm{FeSO}_{4} \cdot 7 \mathrm{H}_{2} \mathrm{O}$ ), $37.5 \mathrm{mg}$; I (as $\mathrm{KI}$ ), $0.83 \mathrm{mg}$; Se (as $\mathrm{Na}_{2} \mathrm{SeO}_{3} \cdot 5 \mathrm{H}_{2} \mathrm{O}$ ), $0.23 \mathrm{mg}$ and choline, $1408 \mathrm{mg}$. 
Table 2. Effects of oral administration of essential oils on organ weight of broilers challenged by Lipopolysaccharide

\begin{tabular}{lccccc}
\hline Items & T1 & T2 & T3 & T4 & T5 \\
\hline Liver (g) & $45.25 \pm 3.96$ & $46.80 \pm 6.41$ & $44.60 \pm 1.83$ & $45.22 \pm 5.50$ & $45.75 \pm 4.50$ \\
Spleen (g) & $1.38 \pm 0.33 b$ & $1.85 \pm 1.42 a$ & $1.32 \pm 0.25 b$ & $1.65 \pm 0.16 a$ & $1.44 \pm 0.16 b$ \\
Bursa (g) & $1.24 \pm 0.39 b$ & $1.95 \pm 0.20 a$ & $1.35 \pm 0.61 b$ & $1.45 \pm 0.32 b$ & $1.39 \pm 0.88 b$ \\
\hline
\end{tabular}

Note: Means within a row not sharing a lowercased italic letter differ significantly at the $\mathrm{P}<0.05$ level. 
Table 3. Effects of oral administration of essential oils on blood metabolites of broilers challenged by Lipopolysaccharide

\begin{tabular}{cccccc}
\hline Items & T1 & T2 & T3 & T4 & T5 \\
\hline IgG $(\mathrm{mg} / \mathrm{mL})$ & $219.40 \pm 35.31 b$ & $250.80 \pm 21.22 a$ & $232.80 \pm 25.63 a b$ & $235.00 \pm 34.39 a b$ & $248.67 \pm 8.14 a$ \\
WBC $\left(10^{3} / \mu \ell\right)$ & $18.92 \pm 5.47$ & $20.44 \pm 5.26$ & $19.60 \pm 3.47$ & $19.64 \pm 0.96$ & $19.55 \pm 2.31$ \\
Lymphocyte $(\%)$ & $91.84 \pm 2.32 b$ & $101.50 \pm 7.54 a$ & $92.48 \pm 2.29 b$ & $97.37 \pm 7.60 a b$ & $94.40 \pm 1.70 b$ \\
TNF- $\alpha(\mathrm{pg} / \mathrm{mL})$ & $17.70 \pm 2.18 b$ & $25.84 \pm 14.40 a$ & $18.19 \pm 2.66 b$ & $18.04 \pm 3.10 b$ & $18.35 \pm 0.15 b$ \\
\hline
\end{tabular}

Note: Means within a row not sharing a lowercased italic letter differ significantly at the $P<0.05$ level. 
Table 4. Effects of oral administration of essential oils on rectum temperature of broilers challenged by Lipopolysaccharide

\begin{tabular}{|c|c|c|c|c|c|}
\hline Items & $\mathrm{T} 1$ & $\mathrm{~T} 2$ & $\mathrm{~T} 3$ & $\mathrm{~T} 4$ & T5 \\
\hline \multicolumn{6}{|l|}{ Rectum temperature, ${ }^{\circ} \mathrm{C}$} \\
\hline & $40.86 \pm 0.09$ & $40.54 \pm 0.52$ & $40.92 \pm 0.96$ & $40.50 \pm 0.30$ & $40.50 \pm 0.30$ \\
\hline \multicolumn{6}{|l|}{ (Before LPS injection) } \\
\hline \multicolumn{6}{|l|}{ Rectum temperature, ${ }^{\circ} \mathrm{C}$} \\
\hline & $40.36 \pm 0.55 b$ & $42.38 \pm 1.19 a$ & $40.86 \pm 0.23 b$ & $40.97 \pm 0.59 b$ & $40.53 \pm 0.65 b$ \\
\hline (After LPS injection) & & & & & \\
\hline
\end{tabular}

Note: Means within a row not sharing a lowercased italic letter differ significantly at the $P<0.05$ level. 
Table 5. Effects of oral administration of essential oils on microbial enumeration in intestine of broilers challenged by Lipopolysaccharide

\begin{tabular}{cccccc}
\hline \multicolumn{1}{c}{ Items } & T1 & T2 & T3 & T4 & T5 \\
\hline Lactobacillus $(\log 10 \mathrm{cfu} / \mathrm{g})$ & $8.50 \pm 0.48$ & $8.04 \pm 0.17$ & $8.60 \pm 0.42$ & $8.89 \pm 0.54$ & $9.05 \pm 0.16$ \\
Salmonella $\quad(\log 10 \mathrm{cfu} / \mathrm{g})$ & $6.27 \pm 1.23 b$ & $7.22 \pm 0.26 a$ & $5.61 \pm 0.28 b$ & $5.68 \pm 0.41 b$ & $5.40 \pm 0.35 b$ \\
E. coli $(\log 10 \mathrm{cfu} / \mathrm{g})$ & $6.72 \pm 0.73 b$ & $7.82 \pm 0.35 a$ & $6.42 \pm 1.18 b$ & $6.92 \pm 0.80 a b$ & $6.54 \pm 0.28 b$ \\
\hline
\end{tabular}

Note: Means within a row not sharing a lowercased italic letter differ significantly at the $P<0.05$ level. 
Table 6. Effects of oral administration of essential oils on small intestine mucosal morphology in broilers challenged by Lipopolysaccharide

\begin{tabular}{lccccc}
\hline Items & T1 & T2 & T3 & T4 & T5 \\
\hline Villi height $(\mu \mathrm{m})$ & $1390.10 \pm 76.04 b$ & $1260.84 \pm 66.32 c$ & $1530.79 \pm 81.48 a$ & $1421.51 \pm 48.77 a b$ & $1448.08 \pm 44.35 a b$ \\
Goblet cell count & $46.00 \pm 3.60 b$ & $41.66 \pm 7.57 c$ & $55.25 \pm 1.26 a$ & $53.00 \pm 1.73 a$ & $54.50 \pm 0.71 a$ \\
\hline
\end{tabular}

Note: Means within a row not sharing a lowercased italic letter differ significantly at the $P<0.05$ level. 